\title{
Increased Prostaglandin Production by Glomeruli Isolated from Rats with Streptozotocin-induced Diabetes Mellitus
}

\author{
Morris Schambelan and Susan Blake \\ Medical Service, San Francisco General Hospital Medical Center, and the \\ Department of Medicine, University of California, San Francisco, California 94110 \\ Josée Sraer, Marcelle Bens, Marie-Paule Nivez, and Fayez Wahbe \\ Institut National de la Santé et de la Recherche Médicale Research Unit 64, Hôpital Tenon, 75020 Paris, France
}

\begin{abstract}
Abnormalities in glomerular function have been observed frequently in the early stages of both clinical and experimental diabetes mellitus. Because prostaglandins (PGs) are present in the glomerulus and have profound effects on glomerular hemodynamics, and because abnormalities of PG metabolism have been noted in other tissues from diabetics, we studied PG biosynthesis in glomeruli obtained from rats in the early stages of experimental diabetes mellitus. Streptozotocin, $60 \mathrm{mg} / \mathrm{kg}$, was administered intravenously to male Sprague-Dawley rats. Control rats received an equal volume of the vehicle. Glomeruli were isolated 9-23 d later. Production of eicosanoids was determined by two methods: by direct radioimmunoassay after incubation of glomeruli under basal conditions and in the presence of arachidonic acid (C20:4), $30 \mu \mathrm{M}$, and by radiometric high-performance liquid chromatography (HPLC) after incubation of glomeruli with $\left[{ }^{14} \mathrm{C}\right] \mathrm{C} 20: 4$. When assessed by radioimmunoassay, mean basal production of both prostaglandin $E_{2}\left(P G E_{2}\right)$ and prostaglandin $F_{2 \alpha}\left(P_{2 \alpha}\right)$ was twofold greater in the diabetic animals whereas production of thromboxane $\mathbf{B}_{2}$ $\left(\mathrm{TXB}_{2}\right)$ was not significantly greater than control. In response to $\mathrm{C20}_{20}$, both $\mathrm{PGE}_{2}$ and $\mathrm{PGF}_{2 \alpha}$ were also greater in the diabetic animals, but these differences were not statistically significant. The increased rate of basal PG production did not appear to be related directly to the severity of the diabetic state as reflected by the degree of hyperglycemia at the time of sacrifice. In fact, the rates of glomerular PG production in the individual diabetic animals correlated inversely with the plasma glucose concentration. The increased rate of PG synthesis did not appear to be due to a nonspecific effect of streptozotocin inasmuch as glomerular PG production was not increased significantly in streptozotocin-treated rats which were made euglycemic by insulin therapy. Furthermore, addition of streptozotocin, 1-10 mM, to the incubation media had no effect on $\mathrm{PGE}_{2}$ production by normal glomeruli. $\mathrm{PGE}_{2}$ production by normal glomeruli was also not influenced by varying
\end{abstract}

This work was presented in part at the annual meeting of the American Federation for Clinical Research in Washington, DC, May 1983, and has appeared in part in abstract form (1983. Clin. Res. 31:440a).

Address requests for reprints to Dr. Schambelan, San Francisco General Hospital.

Received for publication 11 January 1984 and in revised form 1 August 1984.

J. Clin. Invest.

(C) The American Society for Clinical Investigation, Inc.

0021-9738/85/02/0404/09 $\$ 1.00$

Volume 75, February 1985, 404-412 the glucose concentration in the incubation media over a range of 1-40 mM. When metabolism of $\left[{ }^{14} \mathrm{CCC20:4}\right.$ was evaluated by high-performance liquid chromatography conversion to labeled $\mathrm{PGE}_{2}, \mathbf{P G F}_{2 \alpha}, \mathrm{TXB}_{2}$, and hydroxyheptadecatrienoic acid by diabetic glomeruli was two- to threefold greater compared with that in control glomeruli, whereas no significant difference in conversion to 12- and 15-hydroxyeicosatetraenoic acid occurred. These findings indicate that glomerular cyclooxygenase but not lipoxygenase activity was increased in the diabetic animals. A concomitant increase in glomerular phospholipase activity may also have been present to account for the more pronounced differences in PG production noted in the absence of exogenous unlabeled C20:4. These abnormalities in PG biosynthesis by diabetic glomeruli may contribute to the altered glomerular hemodynamics in this pathophysiologic setting.

\section{Introduction}

Abnormalities of glomerular function are prominent features of diabetes mellitus. In addition to the progressive loss of functioning nephrons that occurs in many patients with longstanding type I or insulinopenic diabetes (1), an increase in glomerular filtration rate (GFR) ${ }^{1}$ and renal blood flow has been observed repeatedly in such patients in the earlier stages of this disorder (2-4). Similar increases in both whole kidney (5) and single nephron GFR and glomerular plasma flow rate $(6,7)$ have also been demonstrated in the early stages of an experimental model of diabetes mellitus in the rat, and these hemodynamic alterations have been implicated in the pathogenesis of the glomerular damage that occurs in the later stages of the disease (8).

Recently, decreased responsiveness to the renal vasoconstrictor effects of angiotensin II has also been observed in diabetic rats (9), a finding that may be explained in part by the demonstration that the density of receptors for angiotensin II is decreased in diabetic glomeruli (10). These findings accord with the hypothesis that the abnormalities in glomerular function characteristic of early diabetes may be initiated by alterations in the effects of vasoregulatory hormones such as angiotensin II, which might be expected to affect glomerular hemodynamics (11), as well as by hyperglycemia-induced extracellular volume expansion, structural hypertrophy of the

1. Abbreviations used in this paper: $\mathrm{C} 20: 4$, arachidonic acid; GFR, glomerular filtration rate; HETE, hydroxyeicosatetraenoic acid; HHT, hydroxyheptadecatrienioc acid; HPLC, high-performance liquid chromatography; PG, prostaglandin; $\mathrm{PGD}_{2}, \mathrm{E}_{2}, \mathrm{~F}_{2 \alpha}, \mathrm{I}_{2}$, and 6-keto-PGF $\mathrm{F}_{1 \alpha}$, prostaglandins $D_{2}, E_{2}, F_{2 \alpha}, I_{2}$, and 6-keto-prostaglandin $F_{1 \alpha}$, respectively; $T_{X A_{2}}, T_{X B_{2}}$, thromboxane $A_{2}$ and $B_{2}$, respectively. 
kidney, and altered glucoregulatory hormones (8). That hyperglycemia per se may affect glomerular function is evidenced by the increased GFR documented to occur with infusion of glucose in both normal subjects and insulin-dependent diabetics (12) and by the reduction in elevated levels of GFR and renal plasma flow that results when glucose levels are normalized by acute insulin therapy in type I diabetics, but not when glucose levels are prevented from falling by concomitant glucose infusions (13). In addition to hyperglycemia, the diabetic state is characterized by increased circulating levels of glucoregulatory hormones such as growth hormone and glucagon, both of which can increase GFR (14-16). Thus, the alteration of glomerular function in patients with diabetes is probably multifactorial in nature.

Glomeruli isolated from rat and human renal cortex metabolize arachidonic acid (C20:4) into prostaglandins (PGs) through the cyclooxygenase pathway (17-19). PGs, in turn, have profound effects on glomerular hemodynamics (20-22). Because abnormalities of PG metabolism have been described in various tissues from diabetics (23-26) and have been implicated in the pathogenesis of the vascular complications of this disorder (25-27), we undertook the present study to determine whether or not experimentally induced diabetes mellitus results in qualitative or quantitative changes in glomerular PG production that might contribute to the altered glomerular function in diabetes. Inasmuch as both rat and human glomeruli also metabolize C20:4 to hydroxyeicosatetraenoic acids (HETEs) $(28,29)$, we examined production of these products of lipoxygenase activity in this model.

\section{Methods}

Materials. $\left[{ }^{14} \mathrm{C}\right] \mathrm{C} 20: 4$ (sp act $\left.59.3 \mathrm{mCi} / \mathrm{mmol}\right),\left[{ }^{3} \mathrm{H}\right] \mathrm{PGE}_{2}(160 \mathrm{Ci} /$ mmol), $\left[{ }^{3} \mathrm{H}\right] \mathrm{PGF}_{2 \alpha}(180 \mathrm{Ci} / \mathrm{mmol})$, and $\left[{ }^{3} \mathrm{H}\right] 6-k e t o-\mathrm{PGF}_{1 \alpha}(150 \mathrm{Ci} /$ mmol) were obtained from the Radiochemical Centre (Amersham Corp., Amersham, United Kingdom) and $\left[{ }^{3} \mathrm{H}\right]$ thromboxane $\mathrm{B}_{2}\left(\mathrm{TXB}_{2}\right)$ $(100 \mathrm{Ci} / \mathrm{mmol})$ was obtained from New England Nuclear (Boston, MA). Streptozotocin and C20:4 were purchased from Sigma Chemical Company (St. Louis, MO), PG standards from the Upjohn Company (Kalamazoo, MI) and Seragen, Inc. (Boston, MA), silicic acid from Mallinkrodt Inc. (Paris, KY), and reagent grade solvents from Merck \& Co. (Darmstadt, Federal Republic of Germany). Anti-PGE 2 antiserum was purchased from Institut Pasteur (Paris, France), anti-TXB ${ }_{2}$ antibody was a gift from Dr. Hornych (Paris, France), and anti-PGF ${ }_{2 \alpha}$ antiserum was produced in our laboratory (30). High-performance liquid chromatography (HPLC) was performed on a Varian model 5000 chromatograph (Varian Associates, Inc., Palo Alto, CA) coupled to an ultraviolet detector from Pye Unicam (model LC, Pye Instruments, Cambridge, United Kingdom). Liquid scintillation counting was carried out on a 1211 RACKBETA (LKB Produkter, Bromme, Sweden) or Mark II (Nuclear-Chicago, Des Plaines, IL) instrument using either Picofluor (Packard Instrument Co., Inc., Downers Grove, IL) or ACS2 (Amersham Corp., Arlington Heights, IL) as scintillators. Plasma glucose concentration was measured on a glucose analyzer (Beckman Instruments, Inc., Fullerton, CA).

Animals. Male Sprague-Dawley rats (150-250 $\mathrm{g}$ in body wt) were maintained on standard rat laboratory diet and water ad libitum throughout the study. Diabetes mellitus was induced by intravenous administration of streptozotocin, $60 \mathrm{mg} / \mathrm{kg}$ body weight, dissolved in either saline or sodium citrate buffer $(0.1 \mathrm{M}$ citric acid in $0.145 \mathrm{M}$ $\mathrm{NaCl}, \mathrm{pH} 4.5$ ) at a concentration of $20 \mathrm{mg} / \mathrm{ml}$ immediately before use. Control rats, which were matched for age and weight at the time of streptozotocin administration, received an equal volume of the vehicle. The onset of diabetes was manifested by the development of polyuria and polydypsia within 2-3 d of administration of streptozotocin. Nonfasting plasma glucose samples were obtained one to two times per week by retro-orbital sinus puncture under lightly administered ether anesthesia and by aortic puncture at the time of death. Marked hyperglycemia occurred promptly in the rats that received streptozotocin and tended to increase further during the subsequent weeks of observation (Fig. 1). Only those rats in which plasma glucose levels exceeded $350 \mathrm{mg} / \mathrm{dl}$ were included in the diabetic group.

Additional experiments were carried out to evaluate a possible effect of streptozotocin, rather than of the diabetic state per se, on glomerular PG production. Beginning on day 3, half of each group of diabetic rats were given neutral protamine Hagedorn insulin in doses (2-5 U, subcutaneously, each evening) that were adjusted, on the basis of frequent whole blood glucose measurements (Accu-Chek bG, BioDynamics, Boehringer-Mannheim Corp., Indianapolis, IN), to render them euglycemic. The remaining diabetic rats were untreated, and a third group of age- and weight-matched rats that had received the vehicle served as controls.

Glomerular preparations. Glomeruli were isolated 9-23 d after administration of streptozotocin. Under pentobarbital anesthesia (50 $\mathrm{mg} / \mathrm{kg}$ of body wt, intraperitoneally), the kidneys were perfused with isotonic cold, heparinized saline until blanched $(30-50 \mathrm{ml}$ saline in 2$3 \mathrm{~min}$ ) (31). Glomerular preparations were obtained either from individual rats or from pools obtained from two to three diabetic rats and an equivalent number of control rats. Kidneys from the diabetic and control rats were perfused alternately and no more than six rats were used in a single experiment. No systematic effect of the order of preparation was observed.

Glomeruli were isolated as described previously (17). In brief, for each preparation the renal cortices from one to three rats (two to six kidneys) were dissected and minced to a pastelike consistency. The homogenate was passed successively through a $106-\mu \mathrm{m}$ sieve that excluded the tubules and blood vessels and a $75-\mu \mathrm{m}$ sieve that retained the glomeruli and allowed cells and small debris to pass through. Glomeruli were suspended in ice-cold $20 \mathrm{mM}$ Tris $\mathrm{HCl}$ buffer, $\mathrm{pH}$ 7.4 , containing $135 \mathrm{mM} \mathrm{NaCl}, 10 \mathrm{mM} \mathrm{KCl}, 10 \mathrm{mM}$ sodium acetate, and $5 \mathrm{mM}$ glucose (buffer $\mathrm{A}$ ) and centrifuged at $120 \mathrm{~g}$ for $2 \mathrm{~min}$. The supernatant was discarded and the pellet was resuspended in the same buffer and recentrifuged. The resultant pellet, which consisted of isolated decapsulated glomeruli with $<5 \%$ tubular contamination, was utilized immediately for studies of C20:4 metabolism.

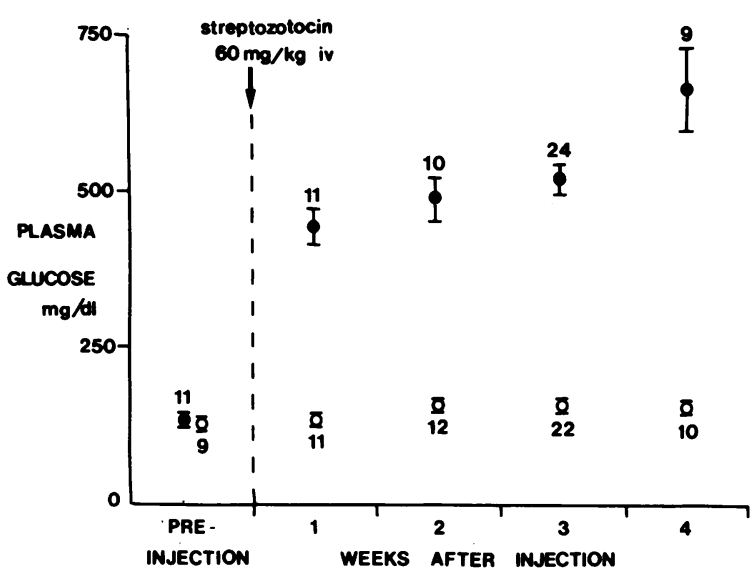

Figure 1. Comparison between the levels of plasma glucose in rats that received streptozotocin, $60 \mathrm{mg} / \mathrm{kg}$, intravenously $(\bullet)$, and those levels observed in control animals (0). The symbols depict the mean \pm SEM of the values obtained in individual rats before and during each of the four weekly time periods after administration of streptozotocin. The numbers next to each symbol refer to the number of rats in which samples were obtained for that period. 
Determination of eicosanoid production. Production of eicosanoids was determined by two methods: by direct radioimmunoassay after incubation of glomeruli under basal conditions and in the presence of C20:4 and by radiometric HPLC after incubation of glomeruli with $\left[{ }^{14} \mathrm{C}\right] \mathrm{C} 20: 4$.

For the studies using direct radioimmunoassay, glomeruli were resuspended in 1-2 $\mathrm{ml}$ of buffer $\mathrm{A}$ with $1 \mathrm{mM} \mathrm{CaCl}_{2}$ and incubated in 250-500- $\mu \mathrm{l}$ aliquots (0.2-0.7 $\mathrm{mg}$ of glomerular protein) in the absence (basal conditions) or presence (stimulated conditions) of C20:4, $10 \mu \mathrm{g} / \mathrm{ml}(30 \mu \mathrm{M})$. Incubations were carried out in room air for 30 min at $37^{\circ} \mathrm{C}$ in a water-bath shaker and were stopped by immediately immersing the tubes in ice followed by centrifugation at $22,000 \mathrm{~g}$ at $4^{\circ} \mathrm{C}$ for $2 \mathrm{~min}$. Supernatants from each tube were collected and frozen until radioimmunoassay was performed. $\mathrm{PGE}_{2}$ and $\mathrm{PGF}_{2 \alpha}$ were measured directly in the supernatant without further purification by the method of Dray et al. (32) and $\mathrm{TXB}_{2}$ by the method of Sors et al. (33).

For the studies of conversion of $\left[{ }^{14} \mathrm{C}\right] \mathrm{C} 20: 4$ to $\mathrm{PG}$ and other eicosanoids, pools of glomeruli from diabetic and control rats were resuspended in buffer $A$ and incubated in 1-ml aliquots $(2.0-5.0 \mathrm{mg}$ of glomerular protein) in the presence of $5 \mathrm{mM} \mathrm{CaCl} 2$ and $1.6 \mu \mathrm{Ci}$ $\left[{ }^{14} \mathrm{C}\right] \mathrm{C} 20: 4$. Incubations were carried out in room air for $30 \mathrm{~min}$ at $37^{\circ} \mathrm{C}$ in a water-bath shaker and were stopped by precipitation with 2 $\mathrm{ml}$ of cold methanol and centrifugation at $22,000 \mathrm{~g}$ for $2 \mathrm{~min}$. The supernatant was removed and the pellet was rewashed with $1 \mathrm{ml}$ of methanol and recentrifuged. The supernatants were pooled, acidified to $\mathrm{pH} 3.0-3.5$ with $1 \mathrm{~N} \mathrm{HCl}$, and after addition of $4 \mathrm{ml}$ of distilled water, were extracted twice with $6 \mathrm{ml}$ of diethyl ether. The ether layers were then pooled and evaporated to dryness in a nitrogen stream.

Column chromatography. Silicic acid column chromatography was performed in glass columns packed with $0.5 \mathrm{~g}$ of silicic acid (100 mesh) suspended in solvent 1 (benzene/ethyl acetate, 60:40, vol/vol). The dry residue from the ether extraction was resuspended in $1 \mathrm{ml}$ of solvent 2 (benzene/ethyl acetate/methanol, 60:40:2, vol/vol/vol) and applied to the column. Two fractions of the sample were collected by successive elution with $10 \mathrm{ml}$ of the following solvents in order: $(a)$ solvent 1 , which elutes unreacted C20:4, HETEs, and hydroxyheptadecatrienoic acid (HHT) and (b) solvent 3 (benzene/ethyl acetate/ methanol, 60:40:20, vol/vol/vol), which elutes PGs. Both fractions were then evaporated to dryness under a nitrogen stream.

To remove unreacted $\mathrm{C} 20: 4$, fraction I was purified further on a glass column packed with $0.5 \mathrm{~g}$ of silicic acid (Silicar CC4) suspended in solvent 4 (hexane/ether, 90:10, vol/vol). The dry residue from fraction I was resuspended in $0.5 \mathrm{ml}$ of solvent 4 and applied to the column. The column was washed with $15 \mathrm{ml}$ of solvent 4 , which elutes unreacted $\mathrm{C} 20: 4$, and then eluted with $15 \mathrm{ml}$ of solvent 5 (ether/ methanol, 95:5, vol/vol) into a glass vial and dried under a nitrogen stream.

HPLC. The purified residue from fraction I was dissolved in HPLC solvent A (hexane/ethanol/acetic acid, 993:6:1, vol/vol/vol), and 100 $\mu l$ was injected directly into the chromatograph. The straight-phase column (MicroPak Si-10, $30 \mathrm{~cm} \times 4 \mathrm{~mm}$ i.d., Varian Associates, Inc.) was eluted with the solvent system: $90 \%$ solvent A and $10 \%$ solvent B (hexane/ethanol/acetic acid, 899:100:1, vol/vol/vol) at a flow rate of $0.8 \mathrm{ml} / \mathrm{min}$; after $20 \mathrm{~min}$ the flow rate was changed to $1.5 \mathrm{ml} / \mathrm{min}$. Fractions were collected every minute and ${ }^{14} \mathrm{C}$-radioactivity of each fraction was measured by liquid scintillation spectrometric techniques. After $35 \mathrm{~min}$, the column was washed with a linear gradient of solvent B (10-100\% in $5 \mathrm{~min})$. The elution of standard hydroxyacids was monitored by measurement of ultraviolet absorbance at $235 \mathrm{~nm}$ and the products identified by co-migration with authentic HETE standards as described previously (29). $\left[{ }^{14} \mathrm{C}\right] \mathrm{HHT}$, produced by reacting $\left[{ }^{14} \mathrm{C}\right] \mathrm{C} 20: 4$ in the presence of platelets, was purified using a reverse-phase system (MicroPak MCH-10, $30 \mathrm{~cm} \times 4 \mathrm{~mm}$ i.d., Varian Associates, Inc.), eluting with HPLC solvent $\mathrm{C}$ (methanol/water/acetic acid, 72.5:27.5:0.01, vol/vol/vol) at a flow rate of $1.2 \mathrm{ml} / \mathrm{min}$.

The purified residue from fraction II was dissolved in HPLC solvent D (water/acetonitrile/benzene/acetic acid, 790:230:2:1, vol/vol/ vol) and $100 \mu \mathrm{l}$ was injected directly into the chromatograph. The reverse-phase column (Spherisorb S5C6, $25 \mathrm{~cm} \times 4.9 \mathrm{~mm}$ i.d., Phase Separations, Mauppauge, NY) was eluted isocratically at a flow rate of $1.8 \mathrm{ml} / \mathrm{min}$ and the products were identified by co-migration with authentic ${ }^{3} \mathrm{H}-\mathrm{PG}$ standards. Fractions were collected every minute and ${ }^{14} \mathrm{C}$-radioactivity of each fraction was measured. After $50 \mathrm{~min}$ the column was washed with pure acetonitrile.

Data analysis. In studies in which the rate of PG production was determined by radioimmunoassay, the results were expressed as picograms/milligram of protein per 30-min incubation. Glomerular protein was measured by the method of Lowry et al. (34) using bovine serum albumin as the standard. In preliminary experiments, it was determined that the ratio of the number of glomeruli to the amount of glomerular protein was not significantly different in diabetic and control animals: diabetic rats, $12.1 \pm 2.8$ glomeruli per microgram of protein, $n=6$; diabetic rats treated with insulin, $11.6 \pm 2.0, n=4$; control rats $15.9 \pm 3.6$, $n=6$.

In studies in which the rates of transformation of $\left[{ }^{14} \mathrm{C}\right] \mathrm{C} 20: 4$ into labeled PGs and other eicosanoids were studied by radiometric HPLC, the results were expressed as counts per minute per milligram of protein per 30-min incubation. The area under the curve for each product was calculated as the sum of the counts per minute for each tube comprising that peak minus the baseline radioactivity level.

Statistical analysis was performed using Student's $t$ test, the MannWhitney test, and linear regression analysis as appropriate (35).

\section{Results}

Determination of $P G$ production by direct radioimmunoassay. Under basal conditions, glomerular PG production was increased in diabetic rats. This difference was apparent both in studies employing glomerular preparations from individual rats, and in those using pools of glomeruli from diabetic and control animals. In the studies performed in individual rats, the mean production rates of both $\mathrm{PGE}_{2}$ and $\mathrm{PGF}_{2 \alpha}$, the major PGs produced by rat glomeruli, were approximately twofold greater in the rats with diabetes whereas that of the $\mathrm{TXB}_{2}$ was not significantly greater than control (Table I). Production of $\mathrm{PGE}_{2}$ was also measured on the supernatant obtained from incubation of pools of glomeruli from diabetic and control rats. In these studies, mean basal $\mathrm{PGE}_{2}$ production was also approximately twofold greater in glomeruli from diabetic animals $(1619 \pm 301$ vs. $707 \pm 93 \mathrm{pg} / \mathrm{mg}$ of protein per 30-min incubation, $n=7, P<0.02$ ).

The increased rate of basal PG production did not appear to be related directly to the severity of the diabetic state as reflected by the degree of hyperglycemia at the time of death. In fact, the rates of glomerular PG production in the individual diabetic animals correlated inversely with the plasma glucose concentration $\left(r=-0.67, P<0.05\right.$ for $\mathrm{PGE}_{2} ; r=-0.88$, $P<0.001$ for $\mathrm{PGF}_{2 \alpha}$ ) (Fig. 2). Furthermore, in separate studies we determined that $\mathrm{PGE}_{2}$ production by normal glomeruli was not influenced by the glucose concentration in the incubation media over a range of $1-40 \mathrm{~mm}(18-720 \mathrm{mg} / \mathrm{dl})$ (Table II).

The increased rate of $P G$ production did not appear to be due to a nonspecific effect of streptozotocin inasmuch as glomerular PG production was not increased significantly in streptozotocin-treated rats made euglycemic with insulin therapy. The mean plasma glucose concentration in those animals $(179 \pm 77 \mathrm{mg} / \mathrm{dl}, n=10)$ did not differ significantly from that of the controls $(160 \pm 4, n=10)$ in contrast to the marked hyperglycemia $(590 \pm 18, n=12)$ in the untreated diabetic rats. Production rates of $\mathrm{PGE}_{2}(845 \pm 206$ vs. $689 \pm 88 \mathrm{pg} / \mathrm{mg}$ of 
Table I. Comparison of Prostaglandin Production by Glomeruli Isolated from Control and Diabetic Rats*

\begin{tabular}{|c|c|c|c|c|c|c|c|c|}
\hline \multirow{2}{*}{$\begin{array}{l}\text { Study } \\
\text { group }\end{array}$} & \multirow[b]{2}{*}{$n$} & \multirow{2}{*}{$\begin{array}{l}\text { Plasma } \\
\text { glucose }\end{array}$} & \multicolumn{2}{|l|}{$\mathrm{PGE}_{2}$} & \multicolumn{2}{|l|}{$\mathrm{PGE}_{2 a}$} & \multicolumn{2}{|l|}{$\mathrm{TXB}_{2}$} \\
\hline & & & Basal & Stimulated & Basal & Stimulated & Basal & Stimulated \\
\hline & & $m g / d l$ & \multicolumn{6}{|c|}{$\mathrm{pg} / \mathrm{mg}$ of protein per 30-min incubation } \\
\hline Diabetic & 10 & $477 \pm 35$ & $1,617 \pm 206$ & $10,110 \pm 1,642 \ddagger$ & $2,179 \pm 290$ & $9121 \pm 1,406 \ddagger$ & $814 \pm 128$ & $1,841 \pm 257 \ddagger$ \\
\hline Control & 13 & $166 \pm 7$ & $869 \pm 81$ & $7,941 \pm 1,166 \ddagger$ & $1,096 \pm 99$ & $6,430 \pm 820 \ddagger$ & $631 \pm 100$ & $1,807 \pm 244 \ddagger$ \\
\hline \multicolumn{9}{|c|}{ Intergroup comparison } \\
\hline & $P$ & $<0.001$ & $<0.005$ & NS & $<0.001$ & NS & NS & NS \\
\hline
\end{tabular}

* Prostaglandin production was assessed by direct radioimmunoassay of the supernatant obtained after incubation of glomeruli for 30 min in the absence (basal conditions) or presence (stimulated conditions) of C20:4, $10 \mu \mathrm{g} / \mathrm{ml}(30 \mu \mathrm{M})$. The values shown are the mean \pm SEM of the results obtained using glomerular preparations from individual rats. Measurements of $\mathrm{TXB}_{2}$ production were carried out on eight of the diabetic and nine of the control preparations. Intergroup comparisons were made using $t$ test for unpaired variables. $\ddagger$ The mean value for prostaglandin production measured under stimulated conditions differed significantly from corresponding basal value at $P<0.001$ ( $t$ test for paired variables).

protein per $30 \mathrm{~min}$ of incubation), $\mathrm{PGF}_{2 \alpha}(884 \pm 156$ vs. $753 \pm 100)$, and $\mathrm{TXB}_{2}(331 \pm 106$ vs. $450 \pm 86)$ also did not differ significantly in these two groups (insulin-treated diabetic rats vs. control), whereas production rates of $\mathrm{PGE}_{2}(1,136 \pm 167)$ and $\mathrm{PGF}_{2 \alpha}(1,383 \pm 252)$, but not of $\mathrm{TXB}_{2}(636 \pm 106)$, were increased significantly $(P<0.05)$ in the untreated diabetic animals. Furthermore, $\mathrm{PGE}_{2}$ production by normal glomeruli was not affected by addition of streptozotocin to the incubation media (Table III) over a range of concentrations (1-10 mM) that have been demonstrated to inhibit glucose-stimulated proinsulin biosynthesis by (36) and to be cytotoxic to (37) pancreatic islet cells in vitro.

Addition of $\mathrm{C} 20: 4$ increased production of both $\mathrm{PGE}_{2}$ and $\mathrm{PGF}_{2 \alpha}$ to 5-10 times the basal values in both the diabetic and control preparations (Table I). Production rates of $\mathrm{TXB}_{2}$

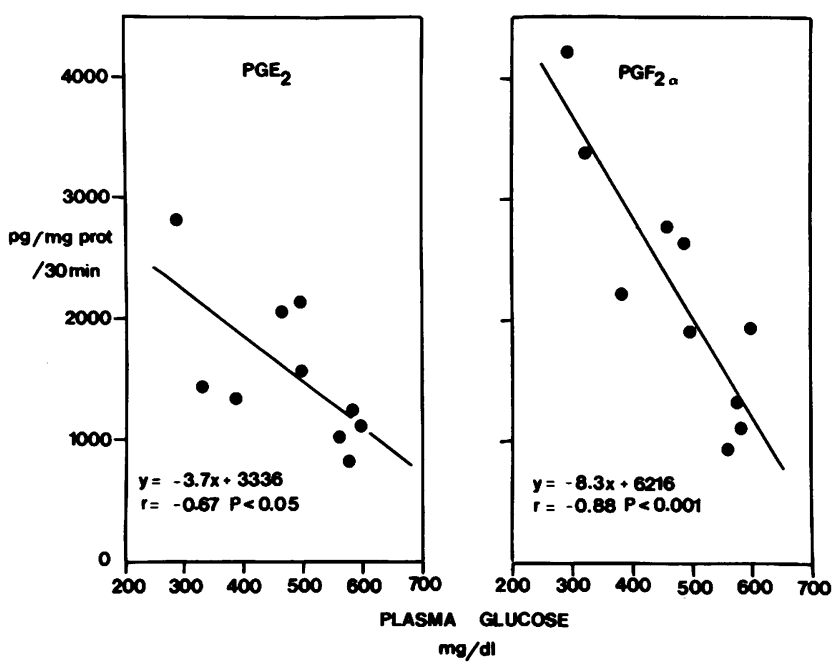

Figure 2. Relationship between the rate of PG production by glomeruli obtained from the individual diabetic rats in Table I and the level of plasma glucose determined in the same animal at the time of death. PG production was estimated by radioimmunoassay of the supernatant obtained after incubation under basal conditions and is expressed as picograms per milligram of glomerular protein per 30min incubation. A significant negative correlation between the plasma glucose concentration and the rate of $P G$ production was present for both $\mathrm{PGE}_{2}$ (left) and $\mathrm{PGF}_{2 \alpha}$ (right), respectively. increased two- to threefold in both groups. Although in the presence of $\mathrm{C} 20: 4$ the mean values of $\mathrm{PGE}_{2}$ and $\mathrm{PGF}_{2 \alpha}$ were $20-40 \%$ higher in the diabetic group, these values did not differ significantly from control values, perhaps owing to the wide scatter in the magnitude of the response to C20:4 seen in both groups.

Identification and quantitation of products by radiometric HPLC. When conversion of $\left[{ }^{14} \mathrm{C}\right] \mathrm{C} 20: 4$ into labeled PGs was examined using a reverse-phase system, no qualitative differences in the profiles obtained from diabetic and control glomeruli were noted. The profiles obtained in control rats in the present study were similar to those reported previously from our laboratory using glomeruli obtained from normal rats (Fig. 3, left). After an initial peak that represents an autooxidation product of $\left[{ }^{14} \mathrm{C}\right] \mathrm{C} 20: 4$, between five and eight peaks could be distinguished during a subsequent 50-60-min elution. Five peaks with retention times of $11,30,36,45$, and $50 \mathrm{~min}$ were identified by co-migration with ${ }^{3} \mathrm{H}$-standards as 6-keto-PGF $1 \alpha, \mathrm{TXB}_{2}, \mathrm{PGF}_{2 \alpha}, \mathrm{PGE}_{2}$, and $\mathrm{PGD}_{2}$, respectively. This pattern of elution was nearly identical in glomeruli obtained from diabetic rats (Fig. 3, right). Whereas no differences in the general patterns of PG production were noted, incorporation of $\left[{ }^{14} \mathrm{C}\right] \mathrm{C} 20: 4$ into the major PGs was increased in the diabetic glomeruli (Table IV).

Table II. Effect of Variation of the Concentration of Glucose in the Incubation Medium on PGE Production by Glomeruli Isolated from Normal Rats*

\begin{tabular}{|c|c|c|c|c|c|c|}
\hline \multirow{3}{*}{$\begin{array}{l}\text { Experiment } \\
\text { no. }\end{array}$} & \multicolumn{6}{|c|}{$\mathrm{PGE}_{2}$ production } \\
\hline & \multicolumn{6}{|c|}{ Glucose concentration, $m M$} \\
\hline & 1 & 2 & 5 & 10 & 20 & 40 \\
\hline & \multicolumn{6}{|c|}{$\mathrm{pg} / \mathrm{mg}$ of protein per $30-$ min incubation } \\
\hline 1 & 734 & 635 & 594 & 544 & 521 & 485 \\
\hline 2 & 672 & 642 & 1210 & 707 & 398 & 917 \\
\hline 3 & 242 & 273 & 234 & 237 & 233 & 343 \\
\hline
\end{tabular}

* $\mathrm{PGE}_{2}$ production was determined by radioimmunoassay of the supernatant obtained from glomerular preparations that had been incubated for $30 \mathrm{~min}$ at $37^{\circ} \mathrm{C}$ after a 20 -min preincubation period at glucose concentrations that ranged from 1 to $40 \mathrm{mM}$. 
Table III. Effect of Addition of Streptozotocin to the Incubation Medium on PGE 2 Production by Glomeruli Isolated from Normal Rats*

\begin{tabular}{|c|c|c|c|c|}
\hline \multirow{3}{*}{$\begin{array}{l}\text { Experiment } \\
\text { no. }\end{array}$} & \multicolumn{4}{|c|}{$\mathrm{PGE}_{2}$ production } \\
\hline & \multicolumn{4}{|c|}{ Streptozotocin concentration, $m M$} \\
\hline & 0 & 1 & 5 & 10 \\
\hline & \multicolumn{4}{|c|}{$\mathrm{pg} / \mathrm{mg}$ of protein per 30-min incubation } \\
\hline \multicolumn{5}{|c|}{ Basal conditions } \\
\hline 1 & 654 & 720 & 778 & 508 \\
\hline 2 & 187 & 217 & 309 & 241 \\
\hline \multicolumn{5}{|c|}{ Stimulated conditions } \\
\hline 1 & 2,189 & 2,530 & 3,497 & 1,794 \\
\hline 2 & 1,229 & 1,198 & 1,480 & 1,103 \\
\hline
\end{tabular}

* $\mathrm{PGE}_{2}$ production was determined by radioimmunoassay of the supernatants obtained from glomerular preparations that had been incubated for $30 \mathrm{~min}$ at $37^{\circ} \mathrm{C}$ in the absence or presence of streptozotocin in doses that ranged from 1 to $10 \mathrm{mM}$. Incubations were performed both in the absence (basal conditions) and presence (stimulated conditions) of $\mathrm{C} 20: 4,10 \mu \mathrm{g} / \mathrm{ml}(30 \mu \mathrm{M})$.

When conversion of $\left[{ }^{14} \mathrm{C}\right] \mathrm{C} 20: 4$ into lipoxygenase products and other eicosanoids was studied using a straight-phase system, there were again no differences in the patterns of ${ }^{14} \mathrm{C}$-products between control and diabetic preparations. As previously reported from our laboratory (20), at the high substrate concentration used in these experiments, glomeruli from normal rats form predominantly 12 - and 15 -HETE, products that elute at

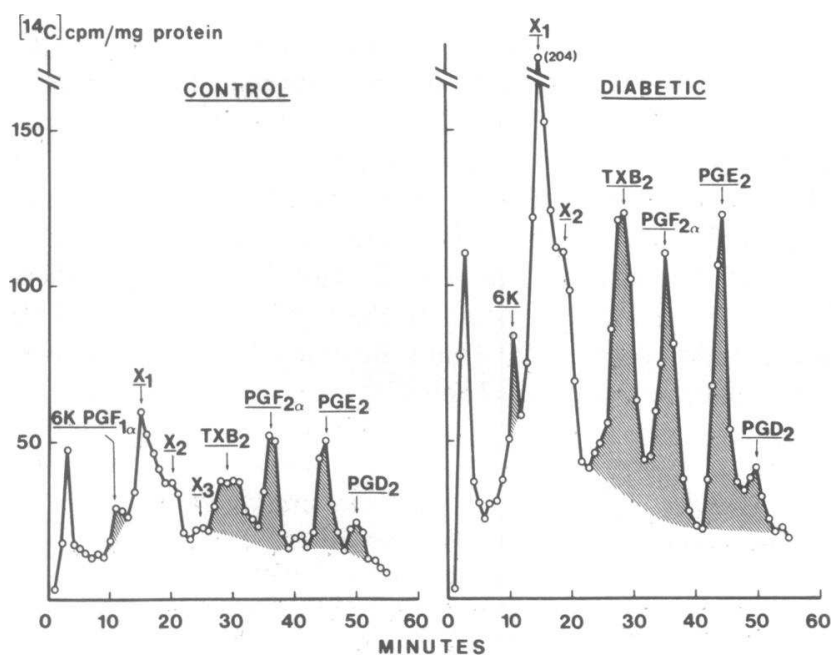

Figure 3. Reverse-phase HPLC of $\left[{ }^{14} \mathrm{C}\right] \mathrm{C} 20: 4$ products formed by incubation of glomeruli isolated from pools of control (left) and diabetic (right) rats. After an initial peak that represents an autooxidation product of $\left[{ }^{14} \mathrm{C}\right] \mathrm{C} 20: 4$, five peaks (indicated by the shaded areas) with retention times of $11,30,36,45$, and 50 min were identified by comigration with ${ }^{3} \mathrm{H}$-standards as 6-keto-PGF ${ }_{1 \alpha}, \mathrm{TXB}_{2}$, $\mathrm{PGF}_{2 \alpha}, \mathrm{PGE}_{2}$, and $\mathrm{PGD}_{2}$, respectively. Two large peaks $\left(\mathrm{X}_{1}\right.$ and $\left.\mathrm{X}_{2}\right)$ eluting between 6-keto-PGF ${ }_{1 \alpha}$ and $\mathrm{TXB}_{2}$, were also present as noted previously for rat glomeruli (38). These remain unidentified but are thought likely to be products of cyclooxygenase activity inasmuch as they are suppressed by addition of indomethacin to the incubation mixture. On the right panel, the figure in parentheses next to peak $\mathrm{X}_{1}$ indicates the magnitude of this product.
11 and $13 \mathrm{~min}$, directly after a large peak of unreacted C20:4 (Fig. 4, left). A minor peak (eluting at $17 \mathrm{~min}$ ) corresponded to the retention time of 11-HETE. An additional major peak (eluting at $26 \mathrm{~min}$ ) was noted consistently, using the chromatographic system employed in the present studies. This peak co-migrated with both 8-HETE and HHT standards in this system. When this peak was collected and reinjected into a reverse phase system (MicroPak MCH-10), it was evident that the product formed by both the diabetic and control glomeruli was entirely HHT. Similar to the PGs, conversion to HHT was increased in diabetic glomeruli (Table IV). In contrast, no significant difference in the rate of formation of the lipoxygenase products was observed.

\section{Discussion}

The results of our study indicate that the synthesis of PGs is altered in glomeruli isolated from rats with streptozotocininduced diabetes mellitus and that the abnormalities are a consequence of the diabetic state rather than of the agent used to produce it. Production rates of both $\mathrm{PGE}_{2}$ and $\mathrm{PGF}_{2 \alpha}$, the major PGs produced by rat glomeruli, were increased two- to threefold whether estimated by direct radioimmunoassay (Table I) or by incorporation of $\left[{ }^{14} \mathrm{C}\right] \mathrm{C} 20: 4$ into labeled eicosanoids (Table III). Production of $\mathrm{TXB}_{2}$, the stable metabolite of thromboxane $A_{2}\left(T_{X A}\right)$, appeared to also be increased but this difference was only statistically significant in the studies employing radiometric HPLC. The pattern of radiolabeled products formed after incubation with $\left[{ }^{14} \mathrm{C}\right] \mathrm{C} 20: 4$ suggests a specific augmentation of glomerular cyclooxygenase but not lipoxygenase activity. Our data do not exclude a concomitant increase in glomerular phospholipase activity which, if present, might account for the more pronounced difference in PG production noted in the absence of exogenous unlabeled C20:4.

Our finding that glomerular PG synthesis is altered in diabetic rats is in accordance with the numerous observations of abnormalities in PG metabolism that occur in both clinical and experimental diabetes. Increased release of $\mathrm{PGE}_{2}$ and prostaglandin $\mathrm{I}_{2}\left(\mathrm{PGI}_{2}\right)$ by adipocytes in rats with diabetic ketoacidosis has been inferred by the observation that elevated plasma levels of derivatives of these compounds are suppressed by both insulin and 5-methylpyrazole-3-carboxylic acid, two potent and structurally unrelated antilipolytic compounds (39). Abnormalities of eicosanoid metabolism by platelets are also well described in diabetes. Platelets obtained from diabetic patients release more PGE-like material in response to aggregatory stimuli than do those obtained from normal subjects (23). Increased synthesis of $\mathrm{TXA}_{2}$, as gauged by levels of its stable metabolite $\mathrm{TXB}_{2}$, was also found in platelets obtained from humans with diabetes (24) and from rats with both streptozotocin-induced (40) and spontaneous (BB Wistar) diabetes (41). The finding of increased platelet aggregation and release of malonyldialdehyde in newborn infants and their diabetic mothers compared with control mother-neonate pairs provides further evidence of enhanced thromboxane synthesis activity (42). In contrast to increased synthesis of these proaggregatory eicosanoids by platelets, release of the potent antiaggregatory eicosanoid prostacyclin was decreased in arteries (25) and veins (26) of patients with diabetes mellitus, in umbilical arteries of neonates of mothers with either gestational or juvenile-onset diabetes $(43,44)$, and in aortic tissues obtained 
Table IV. Incorporation of $\left[{ }^{14} \mathrm{C}\right] \mathrm{C} 20: 4$ into Labeled Eicosanoids by Glomeruli from Diabetic and Control Rats*

\begin{tabular}{|c|c|c|c|c|c|c|c|c|c|}
\hline \multirow{2}{*}{$\begin{array}{l}\text { Experiment } \\
\text { no. }\end{array}$} & \multirow{2}{*}{$\begin{array}{l}\text { Study } \\
\text { dateł }\end{array}$} & \multirow{2}{*}{$\begin{array}{l}\text { Study } \\
\text { group }\end{array}$} & \multirow{2}{*}{$\begin{array}{l}\text { Glomerular } \\
\text { protein }\end{array}$} & \multicolumn{4}{|l|}{ Prostaglandins } & \multirow[b]{2}{*}{ 12- and 15-HETE } & \multirow[b]{2}{*}{ HHT } \\
\hline & & & & Total & $\mathrm{TXB}_{2}$ & $\mathrm{PGE}_{2 a}$ & $\mathrm{PGE}_{2}$ & & \\
\hline & & & $m g / m l$ & $\mathrm{cpm} / \mathrm{mg}$ of prot & & & & & \\
\hline \multirow[t]{2}{*}{1} & 23 & Diabetic & 4.13 & 2,150 & 481 & 285 & 292 & 2,748 & 3,246 \\
\hline & & Control & 4.95 & 730 & 150 & 111 & 103 & 2,709 & 824 \\
\hline \multirow[t]{2}{*}{2} & 22 & Diabetic & 3.42 & 1,351 & 156 & 300 & 254 & 3,181 & 1,787 \\
\hline & & Control & 3.53 & 1,311 & 141 & 209 & 144 & 3,810 & 1,240 \\
\hline \multirow[t]{2}{*}{3} & 16 & Diabetic & 4.95 & 1,673 & 430 & 388 & 302 & 2,712 & 1,300 \\
\hline & & Control & 3.74 & 648 & 71 & 184 & 136 & 1,640 & 628 \\
\hline \multirow[t]{2}{*}{4} & 15 & Diabetic & 1.98 & 2,647 & 775 & 543 & 375 & 3,527 & 1,987 \\
\hline & & Control & 2.61 & 825 & 187 & 114 & 159 & 3,597 & 1,034 \\
\hline \multirow[t]{3}{*}{5} & 15 & Diabetic & 2.74 & 1,624 & 400 & 231 & 247 & 7,049 & 1,777 \\
\hline & & Control & 2.95 & 1,026 & 293 & 106 & 119 & 4,202 & 1,180 \\
\hline & & Diabetic & $3.44 \pm 0.52$ & $1,889 \pm 229$ & $448 \pm 99$ & $349 \pm 55$ & $294 \pm 23$ & $3,843 \pm 815$ & $2,019 \pm 327$ \\
\hline \multirow[t]{2}{*}{ Mean \pm SEM } & & Control & $3.56 \pm 0.40$ & $908 \pm 119$ & $168 \pm 36$ & $145 \pm 22$ & $132 \pm 10$ & $3,192 \pm 459$ & $981 \pm 114$ \\
\hline & & $P$ value & NS & $<0.01$ & $<0.05$ & $<0.01$ & $<0.01$ & NS & $<0.01$ \\
\hline
\end{tabular}

* Results are expressed as counts per minute per milligram of protein per 30-min incubation. The area under the curve for each product was calculated as the sum of the $\mathrm{cpm}$ for each tube comprising that peak minus the baseline radioactivity level. Values were compared by the Mann-Whitney test. $¥$ Days after administration of streptozotocin or vehicle.

from rats $(45,46)$ and swine $(47)$ with streptozotocin-induced diabetes. In the pancreas a possible role for abnormalities of PG metabolism in the pathophysiology of impaired insulin secretion in diabetics has been inferred from the observation that PGE infusion inhibits glucose-induced acute insulin responses in normal human subjects and infusion of sodium salicylate partially restores the acute insulin response to glucose infusion in type II diabetics (48). Similarly, changes in PG metabolism in lung (49-51), heart (52), and seminal vesicles

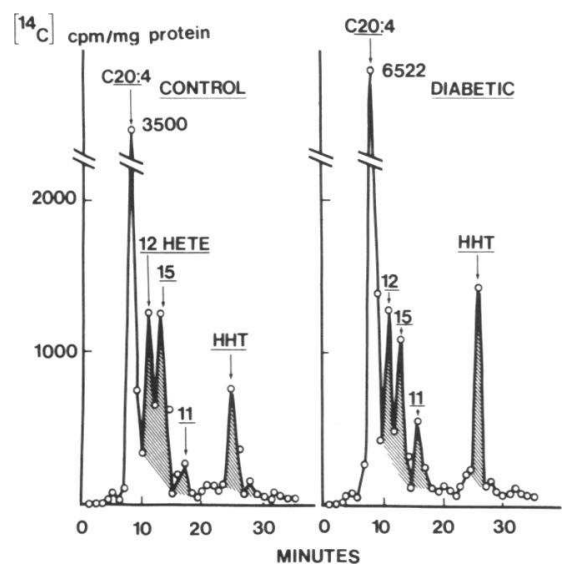

Figure 4. Straight-phase HPLC of $\left[{ }^{14} \mathrm{C}\right] \mathrm{C} 20: 4$ products formed by incubation of glomeruli isolated from pools of control $(l e f t)$ and diabetic (right) rats. After an initial peak of unreacted C20:4, three peaks (indicated by the shaded areas) with retention times of 11,13 , and $17 \mathrm{~min}$ were identified by comigration with authentic standards as 12-HETE, 15-HETE, and 11-HETE, respectively. A fourth peak, eluting at $26 \mathrm{~min}$, co-migrated with both 8-HETE and HHT standards in this system. When this peak was collected and injected into a reverse-phase system, it was determined to be entirely HHT.
(53) may also contribute to altered function of these organs in diabetics.

Despite the substantial evidence for abnormalities in PG production in other tissues from diabetics, relatively little attention has been paid to possible alterations in renal PG metabolism in this disorder. In humans such observations have been limited to measurement of the urinary excretion of $\mathrm{PGE}_{2}$, which has been variously reported to be reduced (54, $55)$ or normal $(56,57)$ in patients with diabetic nephropathy. However, interpretation of even these few reports is made difficult by the uncertainty as to the site of origin of the urinary prostanoids, by the technical issues raised by inclusion of male subjects (58), and by the fact that these studies were performed in the chronic stages of the disease when glomerular function was compromised significantly. In the rat microsomal preparations from whole kidney homogenates obtained in the first two weeks of both alloxan- and streptozotocin-induced diabetes mellitus released less PGE-like material when incubated with C20:4 than those from control animals (59). Production of $\mathrm{PGI}_{2}$ was also decreased in homogenates of renal cortex obtained from rats studied 1-3 mo after administration of streptozotocin (60). It should be noted, however, that results of studies performed on either crude homogenates or microsomal preparations of whole cortex may reflect abnormalities in PG metabolism in structures other than the glomerulus. Thus, Rogers and Larkins (61) reported that release of 6-keto$\mathrm{PGF}_{1 \alpha}$ by glomeruli isolated from diabetic rats was not decreased compared with glomeruli from control rats. In fact, as noted by these investigators, mean production of both 6-keto-PGF 1 a and $\mathrm{PGE}_{2}$ under basal conditions and after stimulation by arachidonate was actually increased in diabetic rats, but the differences did not reach the level of statistical significance. Similar increases in glomerular synthesis of $\mathrm{PGE}_{2}$ and 6-keto$\mathrm{PGF}_{1 \alpha}$ have now been confirmed by Kreisberg and Patel (62) 
and, in preliminary form, by Brown et al. (63), and Chaudhari and Kirschenbaum (64). Taken together with the results of our study, it appears that, at least in the early stages of the disorder, glomerular PG synthesis is increased in glomeruli from diabetic rats.

The results of our studies do not identify the mechanism responsible for the increase in PG production by glomeruli. Inasmuch as PGs may function as modulators of the action of a variety of vasoactive substances, the increased PG synthesis we observed could represent a response to the systemic hemodynamic abnormalities that occur in severe diabetes. Although plasma volume per se is generally normal or increased in this setting (6), salt depletion, attending osmotic diuresis in severe diabetes, could conceivably be present independently of an alteration in intravascular volume. However, when salt depletion was induced in the rat by dietary restriction of $\mathrm{NaCl}$ (31), the pattern of PG synthesis by isolated glomeruli, namely an increase in $\mathrm{PGF}_{2 \alpha}$ and a decrease in $\mathrm{PGE}_{2}$, was clearly different than that observed in our study. Furthermore, the highest PG production rates that we observed occurred in the rats with the least severe degrees of hyperglycemia (Fig. 2), suggesting that the abnormalities were not related quantitatively to the disturbance of osmolality.

Alternatively, the abnormalities in C20:4 metabolism could result from the profound metabolic changes that occur in diabetes. A direct stimulatory effect of hyperglycemia seems unlikely in view of the negative correlation between blood glucose levels and the rate of PG synthesis (Fig. 2) and the absence of a stimulatory effect when the concentration of glucose was increased in the incubation media in vitro (Table II) (62). Furthermore, simply increasing the external concentration of glucose may bear little resemblance to the diabetic state in which intracellular glucose and ATP concentrations may be decreased as a consequence of insulin deficiency. That such hypoglycemic conditions might stimulate PG production is suggested by the finding that release of both $\mathrm{PGE}_{2}$ and $\mathrm{PGF}_{2 \alpha}$ by renal papillae is stimulated by reduction of the glucose concentration of the media (65) and by the addition of inhibitors of glycolysis (66). In other tissues such as vascular endothelium, the interaction between glucose concentration and PG release is even more complex, with stimulation occurring at concentrations between 10 and $30 \mathrm{mM}$ with a subsequent decrease at higher concentrations (67). Production of PGs may be increased by activation of lipolysis as evidenced by the reduction of elevated plasma PG levels that occurred when antilipolytic agents were administered to rats with diabetic ketoacidosis (39). PG production by diabetic tissues might be affected further by deficiency of $\mathrm{C} 20: 4$ stores (68), a finding that might have contributed to the lower rates of PG release in our most severely diabetic animals. That any one or more of the many metabolic abnormalities that comprise the diabetic milieu in vivo could conceivably influence PG production, is suggested by the recent observation that prostacyclin production by human endothelial cells in culture was reduced when cultured in diabetic serum (69).

Whether or not the biochemical abnormalities in glomerular PG metabolism observed in the diabetic animals in the present study contribute to the abnormalities in glomerular function reported by others $(5-10)$ remains to be demonstrated. There is a considerable body of evidence that indicates that the filtration process is modulated by a variety of classic hormonal substances and by locally acting autacoids (11). Certain vaso- active hormones, such as angiotensin II, appear to be generated locally in the kidney as well as in the systemic circulation and may represent a common effector by which many hormones influence the GFR $(11,70)$. PGs, which are also produced locally in the kidney, can influence GFR by modification of the vasoconstrictor effects of angiotensin II (21) and by stimulation of renin secretion and local generation of angiotensin II, which reduces the glomerular capillary ultrafiltration coefficient $\left(K_{f}\right)(70)$. The reduction in $K_{f}$ appears to be mediated by contraction of the glomerular mesangial cell, a cell that contains receptors for and contracts in response to angiotensin II $(71,72)$. PGs, which are secreted by these same mesangial cells (73-75), decrease the contractile responses of whole glomeruli to angiotensin II, and inhibitors of PG synthesis increase the response (76). $\mathrm{TXA}_{2}$, which is also produced locally in the kidney, is a potent vasoconstrictor and can also stimulate glomerular contraction directly (77). Thus, although the preliminary observation that indomethacin reduces single nephron GFR when administered to diabetic rats (78) suggests a net vasodilatory effect of glomerular eicosanoids in this setting, further studies which evaluate the effect of inhibitors of specific enzymes in PG biosynthesis on glomerular hemodynamics will be required to better define the functional role of these compounds in diabetes.

\section{Acknowledgments}

We greatly appreciate the advice and criticism of Dr. Raymond Ardaillou and Dr. Detlef Schlondorff and the secretarial assistance of Ms. Debra Greenblat.

This work was supported by U. S. Public Health Service research grant HL-11046 from the National Heart, Lung, and Blood Institute and by grants from the Institut National de la Santé et de la Recherche Médicale and the Fondation pour la Recherche Médicale.

\section{References}

1. Knowles, H. C., Jr. 1974. Magnitude of the renal failure problem in diabetic patients. Kidney Int. 4(Suppl. 1):S2-S7.

2. Ditzel, J., and M. Schwartz. 1967. Abnormally increased glomerular filtration rate in short-term insulin-treated diabetic subjects. Diabetes. 16:264-267.

3. Mogensen, C. E. 1971. Kidney function and glomerular permeability to macromolecules in early juvenile diabetes. Scand. J. Clin. Lab. Invest. 28:79-90.

4. Christiansen, J. S., J. Gammelgaard, M. Frandsen, and H.-H. Parving. 1981. Increased kidney size, glomerular filtration rate and renal plasma flow in short-term insulin-dependent diabetics. Diabetologia. 20:451-456.

5. Carney, S. L., N. L. M. Wong, and J. H. Dirks. 1979. Acute effects of streptozotocin diabetes on rat renal function. J. Lab. Clin. Med. 93:950-961.

6. Hostetter, T. H., J. L. Troy, and B. M. Brenner. 1981. Glomerular hemodynamics in experimental diabetes mellitus. Kidney Int. 19:410415.

7. Jensen, P. K., J. S. Christiansen, K. Steven, and H.-H. Parving. 1981. Renal function in streptozotocin-diabetic rats. Diabetologia. 21:409-414.

8. Hostetter, T. H., H. G. Rennke, and B. M. Brenner. 1982. The case of intrarenal hypertension in the initiation and progression of diabetic and other glomerulopathies. Am. J. Med. 72:375-380.

9. Reineck, H. J., and J. I. Kreisberg. 1983. Renal vascular response to angiotensin II (AII) in rats with streptozotocin-induced diabetes mellitus (DM). Kidney Int. 23:247A. (Abstr.)

10. Ballermann, B. J., K. L. Skorecki, and B. M. Brenner. 1984. 
Reduced glomerular angiotensin II receptor density in early untreated diabetes mellitus in the rat. Am. J. Physiol. 247:F110-F116.

11. Dworkin, L. D., I. Ichikawa, and B. M. Brenner. 1983. Hormonal modulation of glomerular function. Am. J. Physiol. 244:F95F104.

12. Christiansen, J. S., M. Frandsen, and H.-H. Parving. 1981. Effect of intravenous glucose infusion on renal function in normal man and in insulin-dependent diabetics. Diabetologia. 21:368-373.

13. Christiansen, J. S., M. Frandsen, and H.-H. Parving. 1981. The effect of intravenous insulin infusion on kidney function in insulindependent diabetes mellitus. Diabetologia. 20:199-204.

14. Corvilain, J., and M. Abramow. 1962. Some effects of human growth hormone on renal hemodynamics and on tubular phosphate transport in man. J. Clin. Invest. 41:1230-1235.

15. Parving, H.-H., J. S. Christiansen, I. Noer, B. Tronier, and C. E. Mogensen. 1980. The effect of glucagon infusion on kidney function in short-term insulin-dependent juvenile diabetes. Diabetologia. 19:350-354.

16. Christiansen, J. S., J. Gammelgaard, M. Frandsen, H. Orskov, and H.-H. Parving. 1982. Kidney function and size in type 1 (insulindependent) diabetic patients before and during growth hormone administration for one week. Diabetologia. 22:333-337.

17. Sraer, J., J. D. Sraer, D. Chansel, F. Russo-Marie, B. Kouznetzova, and R. Ardaillou. 1979. Prostaglandin synthesis by isolated rat renal glomeruli. Mol. Cell. Endocrinol. 16:29-37.

18. Hassid, A., M. Konieczkowski, and M. J. Dunn. 1979. Prostaglandin synthesis in isolated rat kidney glomeruli. Proc. Natl. Acad. Sci. USA. 76:1155-1159.

19. Schlondorff, D., S. Roczniak, J. A. Satriano, and V. W. Folkert. 1980. Prostaglandin synthesis by isolated rat glomeruli: effect of angiotensin II. Am. J. Physiol. 238:F486-F495.

20. Baylis, C., W. W. Deen, B. D. Myers, and B. M. Brenner. 1976. Effects of some vasodilator drugs on transcapillary fluid exchange in renal cortex. Am. J. Physiol. 230:1148-1158.

21. Baylis, C., and B. M. Brenner. 1978. Modulation by prostaglandin synthesis inhibitors of the action of exogenous angiotensin II on glomerular ultrafiltration in the rat. Circ. Res. 43:889-898.

22. Schnermann, J., and J. P. Briggs. 1981. Participation of renal cortical prostaglandins in the regulation of glomerular filtration rate. Kidney Int. 19:802-815.

23. Halushka, P. V., D. Lurie, and J. A. Colwell. 1977. Increased synthesis of prostaglandin-E-like material by platelets from patients with diabetes mellitus. $N$. Engl. J. Med. 297:1306-1310.

24. Halushka, P. V., R. C. Rogers, C. B. Loadholt, H. Wohltman, R. Mayfield, S. McCoy, and J. A. Colwell. 1981. Increased platelet prostaglandin and thromboxane synthesis in diabetes mellitus. Horm. Metab. Res. 11(Suppl. 1):7-11.

25. Johnson, M., H. E. Harrison, A. T. Raftery, and J. B. Elder. 1979. Vascular prostacyclin may be reduced in diabetes in man. Lancet. 1:325-326.

26. Silberbauer, K., G. Schernthaner, H. Sinzinger, H. Piza-Katzer, and M. Winter. 1979. Decreased vascular prostacyclin in juvenileonset diabetes. N. Engl. J. Med. 300:366-367.

27. Colwell, J. A., P. V. Halushka, K. E. Sarji, and J. Sagel. 1978. Platelet function and diabetes mellitus. Med. Clin. N. Am. 62:753766.

28. Jim, K., A. Hassid, F. Sun, and M. J. Dunn. 1982. Lipoxygenase activity in rat kidney glomeruli, glomerular epithelial cells, and cortical tubules. J. Biol. Chem. 257:10294-10299.

29. Sraer, J., M. Rigaud, M. Bens, H. Rabinovitch, and R. Ardaillou. 1983. Metabolism of arachidonic acid via the lipoxygenase pathway in human and murine glomeruli. J. Biol. Chem. 258:43254330.

30. Sraer, J., N. Ardaillou, J-D. Sraer, and R. Ardaillou. 1982. In vitro prostaglandin synthesis by human glomeruli and papillae. Prostaglandins. 23:855-864.

31. Chaumet-Riffaud, P., J-P. Oudinet, J. Sraer, C. Lajotte, and R. Ardaillou. 1981. Altered $\mathrm{PGE}_{2}$ and $\mathrm{PGF}_{2 \alpha}$ production by glomeruli and papilla of sodium-depleted and sodium-loaded rats. Am. J. Physiol. 241:F517-F524.

32. Dray, F., B. Charbonnel, and J. Maclouf. 1975. Radioimmunoassay of prostaglandins $F \alpha, E_{1}$ and $E_{2}$ in human plasma. Eur. $J$. Clin. Invest. 5:311-318.

33. Sors, H., P. Pradelles, F. Dray, M. Rigaud, J. Maclouf, and P. Bernard. 1978. Analytical methods for thromboxane $B_{2}$ measurement and validation of radioimmunoassay by gas liquid chromatographymass spectrometry. Prostaglandins. 16:277-290.

34. Lowry, O. H., N. J. Rosebrough, A. L. Farr, and R. J. Randall. 1951. Protein measurement with the Folin phenol reagent. J. Biol. Chem. 193:265-275.

35. Zar, J. H. 1974. Biostatistical Analysis. Prentice Hall, Inc., Engelwood, NJ. 620 pp.

36. Sandler, S., and A. Andersson. 1982. The partial protective effect of the hydroxyl radical scavenger dimethyl urea on streptozotocininduced diabetes in the mouse in vivo and in vitro. Diabetologia. 23:374-378.

37. Kromann, H., M. Christy, A. Lernmark, M. Nedergaard, and J. Nerup. 1982. The low dose streptozotocin murine model of type 1 (insulin-dependent) diabetes mellitus: studies in vivo and in vitro of the modulating effect of sex hormones. Diabetologia. 22:194-198.

38. Sraer, J., W. Siess, L. Moulonguet-Doleris, J.-P. Oudinet, F. Dray, and R. Ardaillou. 1982. In vitro prostaglandin synthesis by various rat renal preparations. Biochim. Biophys. Acta. 710:45-52.

39. Axelrod, L., and L. Levine. 1982. Plasma prostaglandin levels in rats with diabetes mellitus and diabetic ketoacidosis. Diabetes. 31:994-1001.

40. Gerrard, J. M., M. J. Stuart, G. H. R. Rao, M. W. Steffes, S. M. Mauer, D. M. Brown, and J. G. White. 1980. Alteration in the balance of prostaglandin and thromboxane synthesis in diabetic rats. J. Lab. Clin. Med. 95:950-958.

41. Subbiah, M. T. R., and D. Deitemeyer. 1980. Altered synthesis of prostaglandins in platelet and aorta from spontaneously diabetic Wistar rats. Biochem. Med. 23:231-235.

42. Stuart, M. J., H. Elrad, J. E. Graeber, D. O. Hakanson, S. G. Sunderji, and M. K. Barvinchak. 1979. Increased synthesis of prostaglandin endoperoxides and platelet hyperfunction in infants of mothers with diabetes mellitus. J. Lab. Clin. Med. 94:12-17.

43. Stuart, M. J., S. G. Sunderji, and J. B. Allen. 1981. Decreased prostacyclin production in the infant of the diabetic mother. J. Lab. Clin. Med. 98:412-416.

44. Dadak, C., A. Kefalides, H. Sinzinger, and G. Weaver. 1982. Reduced umbilical artery prostacyclin formation in complicated pregnancies. Am. J. Obstet. Gynecol. 144:792-795.

45. Harrison, H. E., A. H. Reece, and M. Johnson. 1978. Decreased vascular prostacyclin in experimental diabetes. Life Sci. 23:351-356.

46. Rogers, S. P., and R. G. Larkins. 1981. Production of 6-oxoprostaglandin $F_{1 \alpha}$ by rat aorta: influence of diabetes, insulin treatment, and caloric deprivation. Diabetes. 30:935-939.

47. Silberbauer, K., P. Clopath, H. Sinzinger, and G. Schernthaner. 1980. Effect of experimentally induced diabetes on swine vascular prostacyclin $\left(\mathrm{PGI}_{2}\right)$ synthesis. Artery. 8:30-36.

48. Robertson, R. P., and M. Chen. 1977. A role for prostaglandin $E$ in defective insulin secretion and carbohydrate intolerance in diabetes mellitus. J. Clin. Invest. 60:747-753.

49. Lubawy, W. C., and M. Valentovic. 1982. Streptozocin-induced diabetes decreases formation of prostacyclin from arachidonic acid in intact rat lungs. Biochem. Med. 28:290-297.

50. Tsai, M. Y., L. E. Schallinger, M. W. Josephson, and D. M Brown. 1982. Disturbance of pulmonary prostaglandin metabolism in fetuses of alloxan-diabetic rabbits. Biochim. Biophys. Acta. 712:395399.

51. Watts, I. S., J. T. Zakrzewski, and Y. S. Bakhle. 1982. Altered prostaglandin synthesis in isolated lungs of rats with streptozotocininduced diabetes. Thromb. Res. 28:333-342.

52. Rösen, P., and K. Schrör. 1980. Increased prostacyclin release 
from perfused hearts of acutely diabetic rats. Diabetologia. 18:391394.

53. Kandil, A., S. Fouad, and S. Samaan. 1982. Diabetes versus prostaglandin activity in the seminal vesicles. In Proceedings of the 5th International Conference on Prostaglandins, Florence, Italy. 113.

54. Norby, L. H., J. Weidig, P. Ramwell, L. Slotkoff, and W. Flamenbaum. 1978. Possible role for impaired renal prostaglandin production in pathogenesis of hyporeninaemic hypoaldosteronism. Lancet. 2:1118-1122.

55. Tan, S. Y., R. Shapiro, R. Franco, H. Stockard, and P. J. Mulrow. 1979. Indomethacin-induced prostaglandin inhibition with hyperkalemia. A reversible cause of hyporeninemic hypoaldosteronism. Ann. Intern. Med. 90:783-785.

56. Hahn, J., R. Zipser, P. Zia, M. Tuck, M. Golub, and R. Horton. 1980. Induction of renin release by exogenous prostaglandins in hyporeninemic hypoaldosteronism. Prostaglandins. 20:15-23.

57. Farese, R. V., M. Rodriguez-Colome, and B. C. O'Malley. 1980. Urinary prostaglandins following frusemide treatment and salt depletion in normal subjects and subjects with diabetic hyporeninaemic hypoaldosteronism. Clin. Endocrinol. 13:447-453.

58. Patrono, C., Å. Wennmalm, G. Ciabattoni, J. Nowak, F. Pugliese, and G. A. Cinotti. 1979. Evidence for an extra-renal origin of urinary prostaglandin $\mathrm{E}_{2}$ in healthy men. Prostaglandins. 18:623629.

59. Hoult, J. R. S., and P. K. Moore. 1980. Prostaglandin synthesis and inactivation in kidneys and lungs of rats with experimental diabetes. Clin. Sci. 59:63-66.

60. Harrison, H. E., A. H. Reece, and M. Johnson. 1980. Effect of insulin treatment on prostacyclin in experimental diabetes. Diabetologia. 18:65-68.

61. Rogers, S. P., and R. G. Larkins. 1982. Production of 6-oxoprostaglandin $F_{1 \alpha}$ and prostaglandin by isolated glomeruli from normal and diabetic rats. Br. Med. J. 284:1215-1217.

62. Kreisberg, J. E., and P. Y. Patel. 1983. The effects of insulin, glucose and diabetes on prostaglandin production by rat kidney glomeruli and cultured glomerular mesangial cells. Prostaglandins Leukotrienes Med. 11:431-442.

63. Brown, D. M., J. M. Gerrard, J. Peller, G. H. R. Rao, and J. B. White. 1980. Glomerular prostaglandin metabolism in diabetic rats. Diabetes. 29(Suppl):55A. (Abstr.)

64. Chaudhari, A., and M. A. Kirschenbaum. 1983. Effect of experimental diabetes mellitus (DM) on eicosanoid biosynthesis in isolated rat glomeruli. Program of the American Society of Nephrology, 16th Annual Meeting Washington, DC. 189A. (Abstr.)

65. Tannenbaum, J., B. J. Sweetman, A. S. Nies, K. Aulsebrook, and J. A. Oates. 1979. The effect of glucose on the synthesis of prostaglandins by the renal papilla of the rat in vitro. Prostaglandins. 17:337-350.

66. Tannenbaum, J. S. 1980. Prostaglandins: a study of their effects on the kidney and factors controlling their release. Ph.D. Thesis, Washington University School of Medicine, St. Louis, MO.

67. Jeremy, J. Y., D. P. Mikhailidis, and P. Dandona. 1983. Simulating the diabetic environment modifies in vitro prostacyclin synthesis. Diabetes. 32:217-221.

68. Holman, R. T., S. B. Johnson, J. M. Gerrard, S. M. Mauer, S. Kupcho-Sandberg, and D. M. Brown. 1983. Arachidonic acid deficiency in streptozotocin-induced diabetes. Proc. Natl. Acad. Sci. USA. 80:23752379.

69. Paton, R. C., R. Guillot, Ph. Passa, and J. Canivet. 1982. Prostacyclin production by human endothelial cells cultured in diabetic serum. Diabete. Metab. 8:323-328.

70. Schor, N., I. Ichikawa, and B. M. Brenner. 1981. Mechanisms of action of various hormones and vasoactive substances on glomerular ultrafiltration in the rat. Kidney Int. 20:442-451.

71. Foidart, J., J. Sraer, F. Delarue, P. Mahieu, and R. Ardaillou. 1980. Evidence for mesangial glomerular receptors for angiotensin II linked to mesangial cell contractility. FEBS (Fed. Eur. Biochem. Soc.) Lett. 121:333-339.

72. Ausiello, D. A., J. I. Kreisberg, C. Roy, and M. J. Karnovsky. 1980. Contraction of cultured rat glomerular cells of apparent mesangial origin after stimulation with angiotensin II and arginine vasopressin. J. Clin. Invest. 65:754-760.

73. Sraer, J., J. Foidart, D. Chansel, P. Mahieu, B. Kouznetzova and R. Ardaillou. 1979. Prostaglandin synthesis by mesangial and epithelial glomerular cultured cells. FEBS (Fed. Eur. Biochem. Soc.) Lett. 104:420-424.

74. Kreisberg, J. I., M. J. Karnovsky, and L. Levine. 1982. Prostaglandin production by homogeneous cultures of rat glomerular epithelial and mesangial cells. Kidney Int. 22:355-359.

75. Scharschmidt, L. A., and M. J. Dunn. 1983. Prostaglandin synthesis by rat glomerular mesangial cells in culture. Effects of angiotensin II and arginine vasopressin. J. Clin. Invest. 71:1756-1764.

76. Scharschmidt, L. A., E. Lianos, and M. J. Dunn. 1983. Arachidonate metabolites and the control of glomerular function. Fed. Proc. 42:3058-3063.

77. Scharschmidt, L. A., M. Simonson, and M. J. Dunn. 1984. The effects of thromboxane $A_{2}\left(T_{X A_{2}}\right)$ or endoperoxide (EP) analogues on rat glomerular planar surface area (GPSA). Kidney Int. 25:336A. (Abstr.)

78. Jensen, P. K., K. Steven, H. Blaehr, J. Sandahl-Christiansen, and H.-H. Parving. 1983. The effects of indomethacin on glomerular hemodynamics in experimental diabetes. Clin. Res. 31:431A. (Abstr.) 